\title{
Estimation of Modal Shift Potential for a New Form of Dial-A-Ride Service
}

\author{
Banihan Gunay and Kadir Akgol \\ Akdeniz University, Turkey \\ Ingmar Andreasson \\ Royal Institute of Technology, Sweden \\ Serdal Terzi \\ Suleyman Demirel University, Turkey
}

\begin{abstract}
The concept of a dynamic and flexible Intelligent Subscription Bus Service (I-Service) was developed, and two integrated questionnaires were conducted among the commuters of a large university campus. To determine travel times to the campus by I-Service, a digital urban road network map with travel time databases was produced, and software was developed to calculate optimum routes using these databases. Travel times for each participant were determined by the shortest travel time principle. The proposed hypothetical service was introduced to participants, and anticipated advantages for each participant were reported back to them by means of a second questionnaire to determine if they would prefer using I-Service. As a result, a 49\% modal shift potential from all other modes in general and a $52 \%$ modal shift potential from private car to I-Service were found.
\end{abstract}

Keywords: Flexible public transport, optimum route, modal shift, road network map, dial-a-ride

\section{Introduction}

Today, people favor private cars and regard conventional public transport as a last solution. The primary reason for this is the inconvenience of public transport, including inappropriate routes, lack of services, lack of stops within walking distance, waiting at stops (especially in poor weather), lack of information on arrival times, in-vehicle crowding, shortcomings of payment systems, and excessive stops, all of which vary from place to place. The inability of conventional public transport to deter people from using private cars and the increase in citizen demand for private cars cause traffic problems, and infrastructure investments to eliminate these traffic problems require significant 
expenditures. Traffic jams, which occur as cities become building sites and alternative roads are inadequate, show that it is necessary to find alternative solutions to traffic problems. Proposals and services that enable people to favor public transport over private cars are the strongest of these alternatives.

To solve the transport problems experienced in urban areas in the recent years, various studies have been conducted in travel demand management, which aims to supervise demand rather than create additional demand through the construction of new roads. Travel demand management can be defined as shaping the available transport infrastructure through small investments that will allow citizens to use it more efficiently and ensure that journeys will shift to fuller and higher-capacity vehicles (Ozsoy 2005). In parallel with these objectives, orientation toward flexible transport services instead of fixed-route transport is among the important issues that will make the use of public transport more efficient. Flexible transport services have no fixed routes and no specified boarding/alighting points and times and are carried out by vehicles with a capacity of 4-20 people (Josselin et al. 2009). They aim to implement service that provides the best balance between unit cost and service quality and that provide an opportunity of offering comfort similar to the comfort of a private car (Hatipoglu et al. 2007; Akgol et al. 2014).

A flexible urban mode of transport to compete with the use of private cars should not be considered a competitor of, but complementary to, conventional public transport and should enhance the attractiveness of public transport. This mode is more flexible in terms of route and time than conventional public transport (Finn 2012) and includes on-demand transport, shared taxi, service vehicles of establishments, vehicle sharing, and group transport for the mobility impaired. In such systems, routes are determined according to incoming demand and shortest route optimization. The type of vehicle may vary by density and demand, and the method of payment may differ depending on demand by passengers. Reservations to use the service are made via Internet or telephone (Brake et al. 2007). Flexible public transport also is a comfortable transport option for those who do not own a private car or who are unable to drive or own a private car and is a good travel alternative for those who have difficulty using available public transport. It is a strong alternative to the use of private cars and encourages public transport (Hatipoglu et al. 2007).

Mulley et al. (2012) emphasized the necessity of encouraging the application of flexible public transport services and proposed a number of solutions to overcome the difficulties faced by these services in Australia, Europe and the U.S. Early regular applications of on-demand services were launched in the U.S. in the early 1970s. Currently being implemented in many countries around the world, particularly England, these services are spreading rapidly. Today, in the U.S. alone, there are about 23,000 companies and more than 370,000 vehicles serving in this mode of transport (Hatipoglu et al. 2007). Many local governments and public transport operators in England and Ireland use flexible transport service for social improvement, especially in areas in which public transport is difficult (Kamruzzaman et al. 2011); the service generally has been implemented in rural areas in terms of design and operation. In Switzerland, demandresponsive PubliCar minibuses run in connection with conventional public transport in 
a completely flexible way; they use reservations and serve rural areas and small towns with populations of 5,000-10,000 people in 32 regions. TaxiTubs serves on demand in the Nord-Pas-de Calais region in the northeast of France with a main goal of feeding the bus lines. Anruf Sammel Taxi (AST) runs in some regions of Germany (Nelson et al. 2010). With use in appropriate places at appropriate times and with an appropriate plan after development through research and studies, flexible transport has the potential for becoming a service of crucial importance in the future (Laws et al. 2009).

For passengers, factors such as cost, capacity, time, flexibility, and reliability are important for comparing different services. Considering these factors, passenger demand could be shifted from conventional public transport to flexible transport services (Vedagiri and Arasan 2009). Recent developments in communication technology have helped to alleviate transportation problems by enhancing alternative transport modes (Chow 2014), such as through vehicle position and customer demand determinations in real time, thus making flexible public transport more attractive (Hosni et al. 2014; Jung and Jayakrishnan 2011; Agatz et al. 2011). Dial-a-ride is one of these flexible public transport types.

Psaraftis (1980), Horn (2002), and Sayarshad and Chow (2015) studied dynamism in diala-ride using the "traveling salesman" problem for route selection. In this paper, however, we used the Dijkstra algorithm, as is demonstrated later. Other researchers who used the Dijkstra algorithm for similar problems include Gebeyehu and Takano (2008), Moloo et al. (2013), and Nykl et al. (2014). In this paper, the Dijkstra algorithm was used due to its convenience and simplicity for various programming and computation requirements, such as the capability of evaluating rising demand and instant acceptance/rejection. According to Ramazzotti and Lios (2009), public transport authorities can support decision-makers with specific data and surveys to determine if the service is sustainable from different points of view. Hauser and Wisinewski (1982) studied the future potential of dial-a-ride transportation through questionnaires with no particular reference to modal shift as a result of increased use of the system.

In this paper, we generated the concept of Intelligent Subscription Bus Service (I-Service) and estimated the impact of this service on the rate of preference; in other words, we investigated whether people would favor available modes of transport over a proposed service with an intelligent and flexible vehicle fleet. I-Service is a dynamic and flexible transport service that determines its route according to incoming instant demand. This service can receive reservations at the last moment via Internet or telephone and can offer alternative payment possibilities. This new concept includes an algorithm capable of accepting or rejecting real-time demand (with flexible routes) as opposed to existing systems (especially the subscription buses currently in use in Turkey). These (existing) services operate on a monthly or annual subscription basis; hence, they charge more compared to ordinary public transport services. In addition, they operate only on fixed routes, giving rise to considerably long journey times. I-Service, on the other hand, is conceptualized on a "pay-as-you-go" basis. By optimizing between demand and journey time, overall travel times are kept to a minimum. When I-Service is compared with reserved taxis, the biggest difference is fares, since the seating capacities of taxis are 
much smaller than the I-Service vehicles proposed. Fare cost, therefore, is one of the most important factors affecting demand for such services.

\section{Material and Method \\ Questionnaire I}

A survey was conducted with 606 people on the main campus of Akdeniz University in Antalya, Turkey, to determine the current travel characteristics of passengers who regularly commuted to and from the campus. Using respondent address information, digital maps that showed the need for transport to the campus within different time periods were determined. The optimum number of vehicles required for users of this service, the travel kilometers of the vehicles, and the new transport characteristics of the passengers were determined by modeling the I-Service. Finally, the participants in the survey were individually notified of the information on the new transport characteristics via their email addresses and asked if they would prefer to use the service. In this way, the shift likely to occur in the mode of transport was estimated.

\section{The A-Service Model}

A university campus was selected as the pilot area, and possible users of the system were students, academic staff, and other staff. Participants were asked to provide personal information (e.g., occupation, age, gender, health status) and residence location; the importance they attached to comfort; whether they possessed their own car; their existing travel mode; travel times, days, and hours they commuted; total waiting and travel times of their use of available public transport; and their email addresses. Participant responses were grouped according to their times of commuting to and from the campus, and the groups were geocoded by means of Geographic Information Systems (GIS) according to the address information they provided.

This study aimed to determine the service duration of I-Service during the day and data about the travel times of potential passengers by modeling the concept of I-Service vehicles. For this purpose, information on the speeds that could be performed on the urban road network of Antalya in different time periods was collected. To do this, 10 global positioning system (GPS) devices were placed in approximately 100 vehicles for four months; the GPS devices were monitored online, and the data received were recorded via a central computer. In this way, information on the speeds that could be performed at different times regarding each road link was obtained, and 34 speed maps were created.

The model developed for I-Service aimed to carry as many subscribers as possible at minimum total journey time since time was chosen as the most important parameter. That is, travel time was prevented from exceeding a specific range by increasing the number of vehicles when necessary. Dijkstra's algorithm, which calculates the shortest route from a source node to all other points on a network, was used in the model (Taha 2007). For the model, software was developed in Java to compute the shortest routes between given sets of origin and destination points (Figure 1). 
FIGURE 1.

User interface of software created

in Java

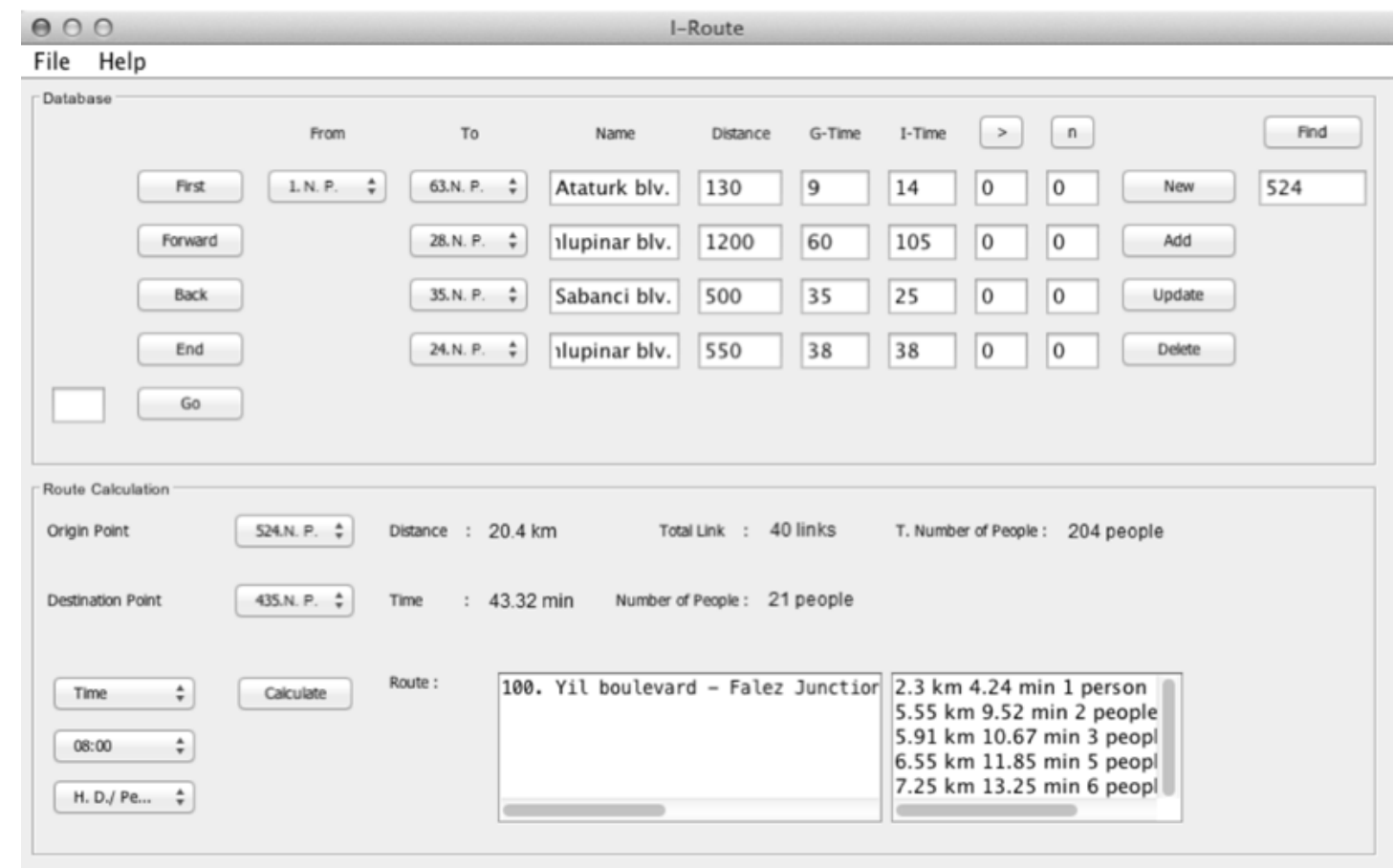

For route calculations, the link travel times data gathered earlier were used, as shown in Table 1.

TABLE 1.

Sample of Link Travel Time

Database

\begin{tabular}{|c|c|c|}
\hline Link & Travel Time & Demand \\
\hline 1 & $A_{1}$ & $B_{1}$ \\
\hline 2 & $A_{2}$ & $B_{2}$ \\
\hline
\end{tabular}

$X=$ Coefficient of resistance for demand $(X=0.001)$.

In quickest route calculations, coefficient encourages

I-Service vehicle to use this link where there is demand;

achieved by intentionally reducing travel times on

these links.

$A_{i}=$ Travel time for link $i$

$B_{i}=$ Number demanded for link $i$

In this case, the link travel times were calculated (based on the Dijkstra algorithm) by the following:

If a call (demand) exists; $\left(B_{1} \neq 0\right)$. Travel time for this link (Link 1$)=$

$$
A_{1} /\left(B_{1}+X\right)
$$

If a call (demand) does not exist, $\left(B_{2}=0\right)$. Travel time for this link (Link 2$)=$

$$
A_{2} / X
$$


After setting up the model, data on the number of people boarding and the identity of the links onto which they boarded were entered into the software database. When the shortest route was calculated according to the Dijkstra algorithm, the vehicle was assigned to the links with service demand. In this way, results were obtained for such questions as how many people were carried by how many vehicles, how many kilometers were traveled in total, and how the travel times turned out for each respondent for "a typical day." Based on the results produced by the software, it was determined that 64 vehicles would be required if all respondents used this service for commuting to and from campus. In this case, a distance of 5,300 kilometres (3,293 miles), on average, was traveled per day.

\section{Cost}

To estimate the single fare for a one-way journey by I-Service, the monthly total cost was computed. As a result of a number of calculations, the details of which are outside the scope of this paper, this figure was determine to be a total of TL $135,500(\$ 52,613)$. The number of people using the service also was calculated to determine the travel fare per capita for this service. For this purpose, data from Questionnaire I on the number of possible users of the service vehicle were used. Responses to "If you had a chance to choose for commuting to and from the campus among the modes of transport classified as public transport, service vehicle, automobile, motorcycle, bicycle, and pedestrian, what would be your order of preference?" from Questionnaire I determined the rates of preference of academic staff, other staff, and students. In total, $100 \%$ of those who preferred service vehicles in the first place and $50 \%$ of those who preferred them in the second place were calculated, and the percentages of possible users were determined. Accordingly, $42.7 \%$ of academic staff, $66.4 \%$ of administrative staff, and $30 \%$ of students were possible users of the service. The number of commuters to and from the campus were 2,081 academic staff, 3,294 other staff, and 37,379 students (obtained from the university). Thus, it was determined that I-Service would have $888+2,188+$ $11,196=14,272$ potential users at Akdeniz University. As this figure is higher than the total passenger capacity, the travel cost would depend only on the rate of occupancy of the vehicles. The correlation between the travel costs per capita for I-Service vehicles and the total rates of occupancy of the vehicles was examined. The service price would be TL 2.50 (\$1), and a profit of TL $0.50(\$ 0.20)$ per capita would be made in the event that the rate of occupancy was around $50 \%$.

\section{Questionnaire II}

A map showing the travel times by I-Service, obtained from the route travel times data, was used (Figure 2) to assist the respondents with Questionnaire II. A total of 377 people participated in the second survey. The travel times and travel costs for I-Service were determined by modeling the I-Service. The current transport characteristics and the new transport characteristics that would occur if the respondent used I-Service, general information on I-Service, and a questionnaire form (Questionnaire II) containing two questions were emailed to the respondents of Questionnaire I (Table 2). 


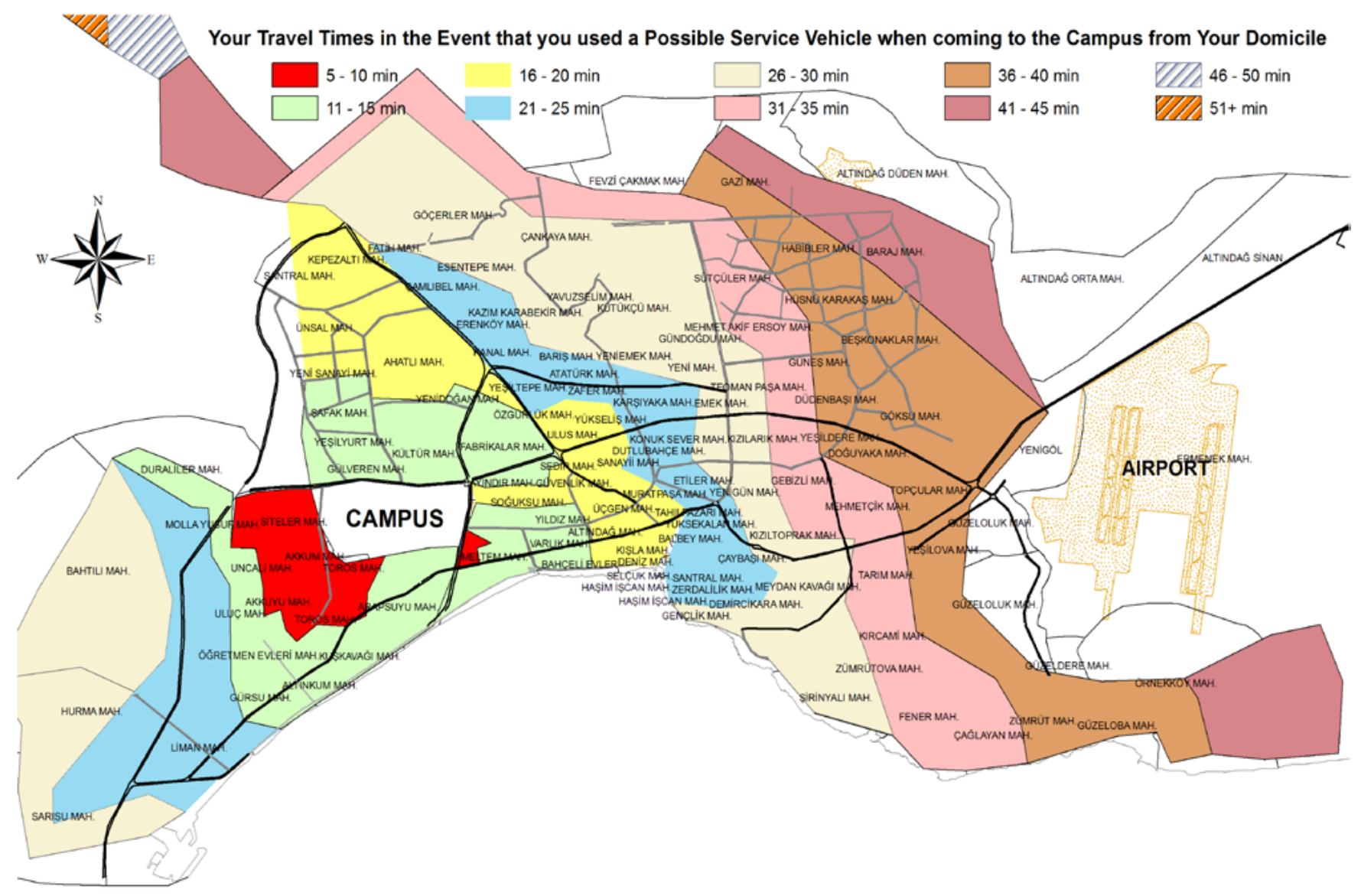

FIGURE 2. Map showing travel times if I-Service used

TABLE 2. Questionnaire II

\begin{tabular}{|l|l|}
\hline \multicolumn{1}{|c|}{ Question } & \multicolumn{1}{c|}{ Response } \\
\hline 1. Would you prefer I-Service? & $\begin{array}{l}\text { Yes, every weekday (..) } \\
\text { Sometimes, a few days (...) } \\
\end{array}$ \\
\hline No (...) \\
\hline If your answer is No, why? & $(\ldots)$ \\
\hline 2. Do you find the projected price of I-Service appropriate? & $\begin{array}{l}\text { Yes (...) } \\
\text { No (...) }\end{array}$ \\
\hline If your answer is No, how much would you pay for this service? & $(\ldots)$ \\
\hline
\end{tabular}

\section{Summary of Surveys}

In summary, the first survey, 606 people were asked about their age, gender, occupation, email address, residential address, existing modes of commuting transport, time spent for commuting, travel schedules, satisfaction levels, desired modes of commuting transport, etc. Based on the address and travel schedule information provided, a hypothetical model was developed for these particular individuals to determine if the proposed I-Service would offer shorter travel times between the same origins 
and destinations at competitive costs. Also in the first survey, we determined the number of people who would use an existing subscription bus service if introduced. To be conservative, in the model, this demand was reduced by $50 \%$ to be able to accommodate potential survey uncertainties. After calculating one-way fares using the model, a second survey was conducted with these 606 respondents, and 560 people expressed whether they would use the proposed I-Service at a particular fare and a commuting travel time between their origins and destinations.

\section{Findings}

According to the results obtained from Questionnaire I, the distribution of the participants was academic staff (40\%), other staff (24\%), and students (36\%). When the distribution was examined by modes of transport, automobile (48\%) was the most preferred mode (Table 3). When the results of both surveys were analyzed, it was found that automobile users had the largest potential to change mode, followed by public transport users; $44 \%$ of public transport users and $34 \%$ of automobile users continued to favor the automobile.

\begin{tabular}{|c|l|c|}
\multirow{1}{*}{$\begin{array}{c}\text { TABLE 3. } \\
\text { Participant Existing } \\
\text { Mode Choice }\end{array}$} & \multicolumn{1}{c|}{ Mode } & Distribution \\
\cline { 2 - 3 } & Automobile & $48 \%$ \\
\cline { 2 - 3 } & Public transport & $26 \%$ \\
\cline { 2 - 3 } & Pedestrian & $18 \%$ \\
\hline & Bicycle & $5 \%$ \\
\hline Motorcycle & $3 \%$ \\
\hline
\end{tabular}

According to the travel maps with time dimensions (e.g., Figure 3), it can be seen that the need for transport to the campus is denser during morning hours. 


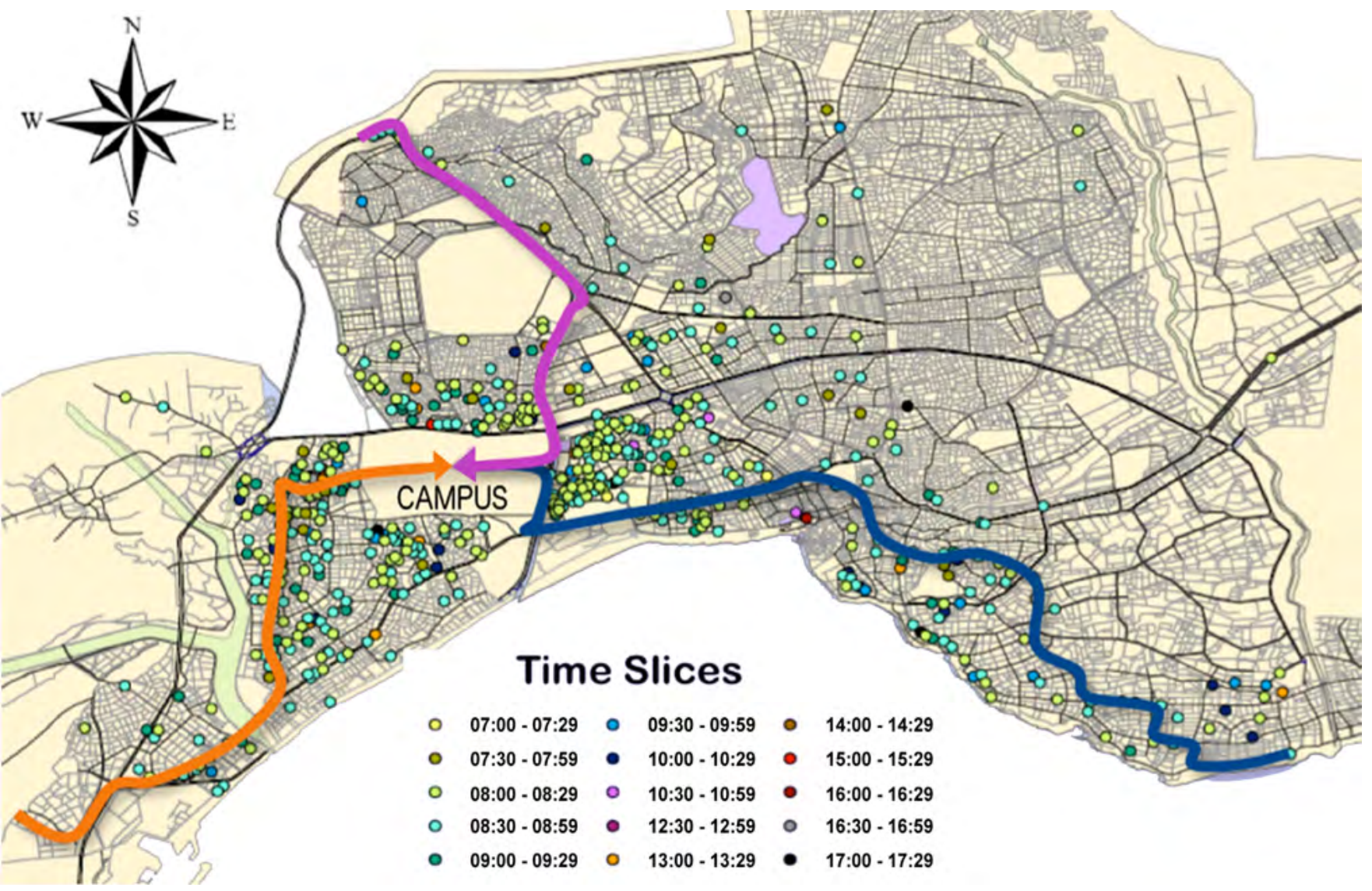

FIGURE 3. Example of demand for transport to campus in different time slices and arbitrarily-selected routes for demonstration purposes 
As a result of the data entered onto the map, the speeds of traffic in different links within the desired time zones can be seen. A sample of these maps is provided in Figure 4.

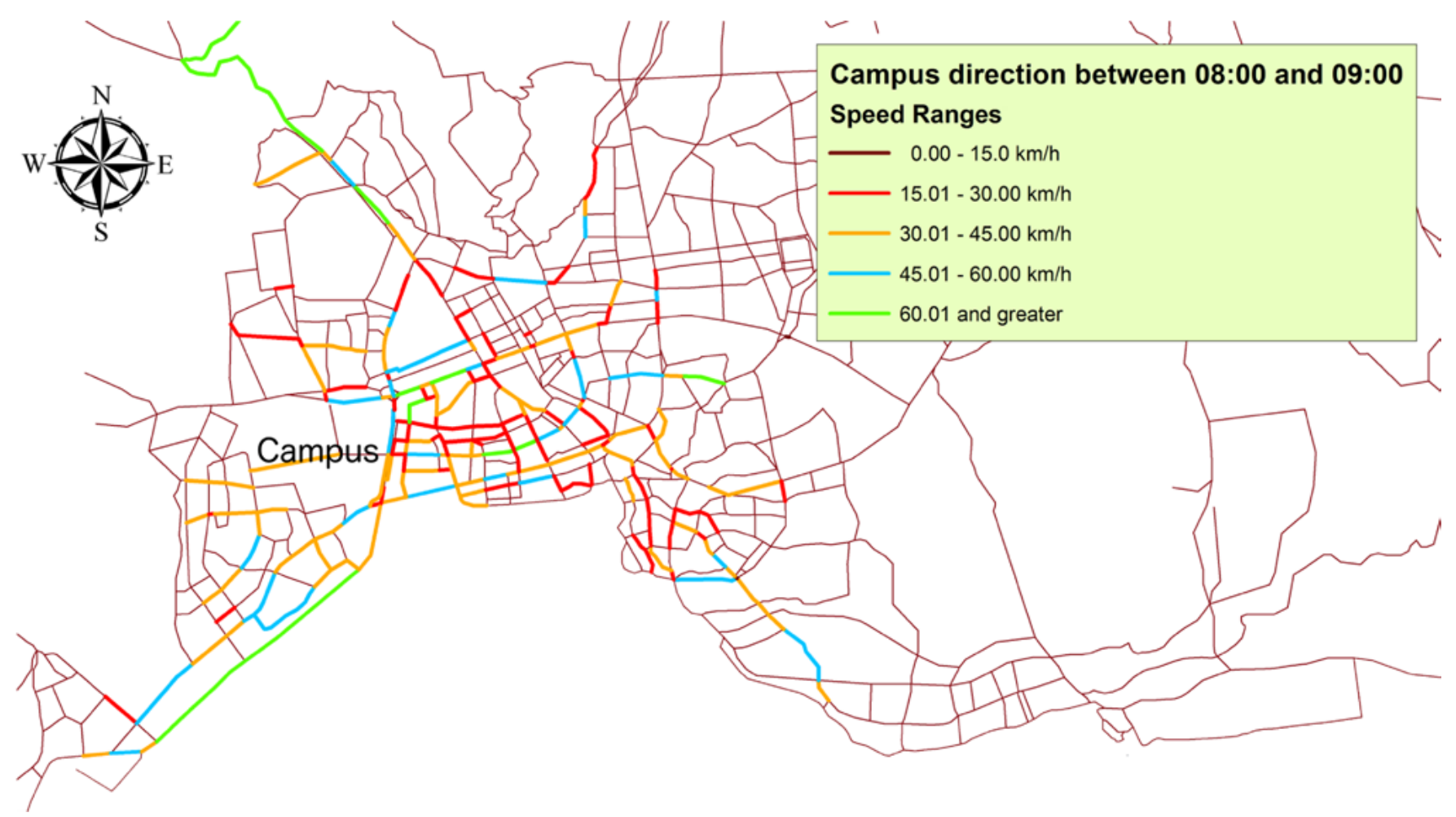

FIGURE 4. Sample of GIS map for speed range

In total, $20 \%$ of the public transport users and $26 \%$ of the automobile users preferred the new service. Reasons why the service was not preferred are presented in Table 4. It was determined that there would be a $49 \%$ modal shift in total (from $48 \%$ to $23 \%$ mode share), which shows the effect on the shift between modes. The service would lead to a $52 \%$ reduction in the use of automobiles, a $59 \%$ reduction in public transport, and a $26 \%$ reduction in pedestrians.

TABLE 4.

Reasons Why l-Service Not Preferred Among Participants

\begin{tabular}{|l|c|}
\hline \multicolumn{1}{|c|}{ Reason } & Percent \\
\hline Familial reasons & $10 \%$ \\
\hline Comfort & $1 \%$ \\
\hline Need for a private car & $12 \%$ \\
\hline Health & $16 \%$ \\
\hline Fare & $23 \%$ \\
\hline Proximity & $25 \%$ \\
\hline Time & $13 \%$ \\
\hline
\end{tabular}


When the effect of the distribution of occupation on the modal shift caused by the I-Service for Akdeniz University campus was examined, it was seen that $51 \%$ of academic staff, $71 \%$ of other staff, and $44 \%$ of students shifted their mode.

Finally, the estimated distributions of the modes before and after the I-Service were compared. As seen in Table 5, the rate of use of automobiles was $48 \%$ before the survey, which dropped to $23 \%$ (second) after the introduction of I-Service, which ranked first (49\%). This indicates that this alternative transport service would be an essential step towards tackling traffic problems.

TABLE 5.

\begin{tabular}{|l|c|c|}
\hline $\begin{array}{c}\text { Mode of } \\
\text { Transport }\end{array}$ & $\begin{array}{c}\text { Participant Distribution } \\
\text { before I-Service }\end{array}$ & $\begin{array}{c}\text { Participant Distribution } \\
\text { after I-Service }\end{array}$ \\
\hline I-Service & - & $49 \%$ \\
\hline Automobile & $48 \%$ & $23 \%$ \\
\hline Public transport & $26 \%$ & $11 \%$ \\
\hline Pedestrian & $18 \%$ & $13 \%$ \\
\hline Bicycle & $5 \%$ & $3 \%$ \\
\hline Motorcycle & $3 \%$ & $1 \%$ \\
\hline
\end{tabular}

These rates indicate that I-Service has a high potential for being preferred. Although these auto trips to/from the university are but a small percentage of total trips in the area and the impact on traffic reduction would be minimal, putting similar services into practice in places such as universities, factories, shopping centers, and airports could impact overall traffic. Also, the scheme may have positive implications on campus parking, where there are currently serious parking issues. All of these potentials will be the subject of further research.

Private car users would financially save $23 \%$ if using I-Service but would experience $16 \%$ longer travel times. Public transport users, however, would pay $45 \%$ more and shorten their travel times by $64 \%$. This shows that the I-Service, as presumed, would be an alternative that is quicker than ordinary public transport and cheaper than private car use.

A sensitivity analysis was carried out on the reliability of the responses to the questionnaire about the willingness to use the I-Service. The results showed that the most effective factors in user choice are the new travel times and fare costs (by 85-95\%); age, gender, occupation, and satisfaction level with existing mode of transport contributed $10-40 \%$. These figures imply that the acceptability potential of the I-Service in application areas other than the study area is likely to be similar.

\section{Discussion and Conclusion}

Today, new modes of transport are being introduced to reduce traffic density and encourage people to use public transport instead of automobiles. Seeking private carbased solutions does not solve the problem but merely defers it to some future time. Conventional public transport remains insufficient for making people switch from their private cars to public transport. Hence, more innovative modes of transport to reduce 
the use of private cars will contribute towards easing the traffic problem. An intelligent transport service with a reservation system that provides a flexible and dynamic public service based on minimum travel times was introduced and modeled in this study. The new I-Service was designed to provide an economical service that offers comfort close to that of a private car, and its effect on the mode of transport was investigated. Information from 606 participants was obtained through two questionnaires conducted on the Internet within the campus of Akdeniz University. The study estimated the required number of vehicles and drivers if respondents were to use the service. Optimum routes, travel times, and kilometers for these routes were determined, as were one-way fares and travel times for each passenger. A total of $49 \%$ of the respondents to Questionnaire II stated that they would use this service at a $2.5 \mathrm{TL}(\$ 1)$ single fare.

Examining the reasons why $51 \%$ of participants did not prefer the I-Service, many factors were influential. The most common reasons included living near the campus, health, and fare. Pedestrians and bicycle users did not prefer this service because they lived near the campus; automobile users did not prefer it because they use their automobile for more than commuting to and from campus; and the public transport users did not prefer it because they thought the fare was high. There was estimated to be a $52 \%$ modal shift from the use of automobiles to the use of I-Service; it would provide a more comfortable service than conventional public transport, which would lead to a $59 \%$ shift from public transport and a $26 \%$ shift from pedestrians. When automobile and motorcycle users were evaluated collectively, the mode shift rose from $52 \%$ to $54 \%$. In total, $51 \%$ of academic staff, $70 \%$ of other staff, and $44 \%$ of students contributed to the mode shift caused by I-Service. These rates indicate that I-Service has a high potential for the future and deserves further and special research attention.

\section{Acknowledgments}

This study was conducted under a research project titled "An Intelligent Subscription Bus Service Concept and the Estimate of Useful Effects on Modal Shift in a Transport System: Computer Modelling in a Pilot Region" (112M019), which was supported by the Turkish Scientific and Technological Research Institute (TUBITAK). The authors would like to thank TUBITAK for this support.

\section{References}

Agatz, N. A. H., A. L. Erera, M. W. P. Savelsbergh, and X. Wang. 2011. "Dynamic RideSharing: A Simulation Study in Metro Atlanta." Transportation Research Part B: Methodological, 45(9): 1450-1464.

Akgol, K., M. M. Aydin, O. Asilkan, and B. Gunay. 2014. "Prediction of Modal Shift Using Artificial Neural Networks." Journal of the Association for Information Communication Technologies, 3(3): 223-229.

Brake, J., C. Mulley, J. D. Nelson, and S. Wright. 2007. Key Lessons Learned from Recent Experience with Flexible Transport Services." Transport Policy, 14(6): 458-466. 
Chow, J. Y. J. 2014. Policy Analysis of Third Party Electronic Coupons for Public Transit Fares." Transportation Research Part A: Policy and Practice, 66(1): 238-250.

Finn, B. 2012. "Towards Large-Scale Flexible Transport Services: A Practical Perspective from the Domain of Paratransit." Research in Transportation Business \& Management, 3: 39-49.

Gebeyehu, M., and S.-e. Takano. 2008. "Demand Responsive Route Design: GIS Application to Link Downtowns with Expansion Areas." Journal of Public Transportation, 11(1): 3.

Hatipoglu, S., E. A. Ozturk, and M. K. Cubuk. 2007. "Demand Responsive Transit System in Urban Transportation: An Information System Design." JESTECH Engineering Science and Technology an International Journal, 10(4): 239-248.

Hauser, J. R., and K. J. Wisniewski. 1982. "Application, Predictive Test, and Strategy Implications for a Dynamic Model of Consumer Response." Marketing Science, 1(2): 143-179.

Horn, M. E. T. 2002. "Fleet Scheduling and Dispatching for Demand-Responsive Passenger Services." Transportation Research Part C: Emerging Technologies, 10(1): 35-63.

Hosni, H., J. Naoum-Sawaya, and H. Artail. 2014. "The Shared-Taxi Problem: Formulation and Solution Methods." Transportation Research Part B: Methodological:, 70: 303318.

Josselin, D., C. Lang, and N. Marilleau. 2009. "Modelling Dynamic Demand Responsive Transport Using an Agent Based Spatial Representation." ECCS '09, European Conference on Complex Systems, University of Warwick, United Kingdom.

Jung, J., and R. Jayakrishnan. 2011. "High-Coverage Point-to-Point Transit: Study of PathBased Vehicle Routing through Multiple Hubs." Transportation Research Record, 2287: 78-87.

Kamruzzaman, M., J. Hine, B. Gunay, and N. Blair. 2011. "Using GIS to Visualise and Evaluate Student Travel Behaviour." Journal of Transport Geography, 19(1): 13-32.

Laws, R., M. P. Enoch, S. G. Ison, and S. Potter. 2009. “Demand Responsive Transport: A Review of Schemes in England and Wales." Journal of Public Transportation, 12(1): 19-37.

Moloo, R. K., H. Moonosawmy, and V. Ramanah. 2013. "An Optimal Route Planner Framework for Mauritius based on Real-Time Constraints." 2013 International Conference on ICT for Smart Society (ICISS): Think Ecosystem Act Convergence: 231236.

Mulley, C., J. Nelson, R. Teal, S. Wright, and R. Daniels. 2012. "Barriers to Implementing Flexible Transport Services: An International Comparison of the Experiences in Australia, Europe and USA." Research in Transportation Business \& Management, 3: 3-11. 
Nelson, J. D., S. Wright, B. Masson, G. Ambrosino, and A. Naniopoulos. 2010. “Recent Developments in Flexible Transport Services." Research in Transportation Economics, 29(1): 243-248.

Nykl, J., M. Jakob, and J. Hrncir. 2014. "Advanced Public Transport Network Analyser." In Schaub, T., G. Friedrich, and B. O'Sullivan (eds.), 21st European Conference on Artificial Intelligence. Amsterdam: IOS Press.

Ozsoy, M. 2005. "A New Model for Para Transit System (Dolmus) in Ankara: Case Study Cayyolu." Master's thesis, Gazi University.

Psaraftis, H. N. 1980. "A Dynamic Programming Solution to the Single Vehicle Manyto-Many Immediate Request Dial-a-Ride Problem." Transportation Science, 14(2): 130-154.

Ramazzotti, D. and A. Lois. 2009. "Sustainable Flexible Transport Services: A Solution against Social Exclusion." Fourth International Conference on Sustainable Development and Planning, May 13-15, Cyprus.

Sayarshad, H. R., and J. Y. J. Chow. 2015. "A Scalable Non-Myopic Dynamic Dial-a-Ride and Pricing Problem." Transportation Research Part B: Methodological, 81(2): 539554.

Taha, H. A. 2007. Operations Research: An Introduction, $9^{\text {th }}$ ed. New York: Pearson.

Vedagiri, P., and V. T. Arasan. 2009. "Modelling Modal Shift Due to the Enhanced Level of Bus Service." Transport, 24(2): 121-128.

\section{About the Authors}

BANIHAN GunaY (banihangunay@akdeniz.edu.tr) is a Professor in the Department of Civil Engineering at Akdeniz University in Antalya, Turkey. He holds a Ph.D. from the University of Newcastle Upon Tyne, UK, and specializes in transportation and traffic engineering and operations.

KADIR AKGOL (kadirakgol@akdeniz.edu.tr) is a Research Assistant and Ph.D. student in the Department of Civil Engineering at Akdeniz University, from which he earned a master's degree in Civil Engineering (Transportation).

INGMAR ANDREASSON (ingmar@logistikcentrum.se) is a Professor Emeritus at the Center for Traffic Research at the Royal Institute of Technology in Stockholm, Sweden, from which he earned a Ph.D. in Computer Simulation Methods and an M.Sc. in Applied Physics.

Serdal TeRzI (serdalterzi@sdu.edu.tr) is a Professor in the Department of Civil Engineering at Suleyman Demirel University in Isparta, Turkey, from which he earned a Ph.D. in Civil Engineering (Transportation) and an M.Sc. in Construction Education (Transportation). 